\title{
ICONOGRAFÍA E IDEOLOGÍA DE LA PINACOTECA DE LA ASAMBLEA LEGISLATIVA DE COSTA RICA (RETRATOS DE JEFES DE ESTADO Y PRESIDENTES DE LA REPÚBLICA)
}

\author{
Iconography and Ideology of the Gallery of the Legislative Assembly of Costa \\ Rica \\ (Portraits of Heads of State and Presidents of the Republic)
}

\section{Andrea Calvo Díaz}

La ideología es una "representación" de la relación imaginaria de los individuos con sus condiciones reales de existencia

Louis Althusser

\section{RESUMEN}

El presente artículo analiza la iconografía e ideología de la Pinacoteca de la Asamblea Legislativa de Costa Rica con el fin de comparar los valores simbólicos e ideales de los retratos de Jefes de Estado y Presidentes de la República. Para este caso, se consideran los siguientes aspectos: elaboración pictórica, marco y acopio retratístico en la notafilia. Se toma en consideración los retratos de José María Castro Madriz y Braulio Carrillo Colina para ejemplificar.

Palabras claves: iconografía, ideología, retrato, política.

\begin{abstract}
This paper analyzes the iconography and ideology of the Gallery of the Legislative Assembly of Costa Rica with the objective to compare symbolic and ideological values of the portraits of Presidents and Heads of State of the Republic. In this case, the following aspects are considered: pictorial elaboration, framework and portraiture collection in other visual manifestations. It takes into consideration the portraits of: José María Castro Madriz and Braulio Carrillo Colina to exemplify.
\end{abstract}

Key Words: iconography, ideology, portrait, politics.

\footnotetext{
${ }^{1}$ Universidad de Costa Rica. Profesora de la Escuela de Estudios Generales. Costa Rica. Correo electrónico: andreaarte06@ gmail.com

Recepción: 28-10-2016 Aceptación: 22-04-2017
} 


\section{Introducción}

A nivel histórico cada cultura asimila su vida cotidiana con la creación de imágenes que proyectan construcciones sociales, políticas, económicas, religiosas, entre otras. Según Belting, “el ser humano es el único lugar en el que las imágenes reciben un sentido vivo" (2007, p. 71), a la vez, de reformular su pasado y convertirlo en memoria. De este modo, la Pinacoteca de la Asamblea Legislativa de Costa Rica se convierte en un módulo visual para recordar la historia política, y por ende, sus protagonistas.

La colección de retratos se inauguró en 1823 con una obra; no obstante, como señala el historiador Luis Felipe Fernández (1997) fue hasta 1983 que nuevamente se vuelve a colgar en el Plenario los retratos de políticos en el Salón del Congreso Legislativo, de forma permanente y conmemorativa cada año de finalización gubernativa. (p. 9)

Actualmente, la Pinacoteca de la Asamblea Legislativa almacena un total de cuarenta y seis retratos, entre ellos Jefes de Estado y Presidentes de la República. Cada retrato apela al recuerdo de administraciones pasadas, a la vez, de recapitular las posiciones políticas de cada gubernativo. Para comprender las implicaciones iconográficas e ideológicas de la colección de retratos se toma en consideración las siguientes secciones ${ }^{2}$ : el retrato y la elaboración pictórica, marco y emblemática de la Pinacoteca de la Asamblea Legislativa de Costa Rica, y por último, el acopio retratístico en otras manifestaciones visuales.

\section{El retrato y la elaboración pictórica: el caso de José María Castro Madriz}

Se comprende por retrato como la expresión visual perceptiva de un sujeto. El artista canaliza la individualidad, el carácter y la psicología del retratado. Asimismo, la obra se circunscribe según las pretensiones del encargo; al menos en el tema costarricense preside un ideal representativo.

\footnotetext{
${ }^{2}$ Se toma en consideración el retrato de José María Castro Madriz y la efigie de Braulio Carrillo Colina para ejemplificar las secciones del presente artículo.
} 
Se toma como ejemplo el retrato de José María Castro Madriz (1843-1885) (último Jefe de Estado y primer Presidente de la República) para realizar un análisis del retrato y proceder pictórico. La representación artística ${ }^{3}$ del retratado deviene de la cultura Occidental; el político es simbolizado en una edad madura, por lo que evoca a un sujeto intelectual y experimentado. Este aspecto coincide con el ideal platónico, el cual sugiere de un gobernante lo siguiente:

(...) puesto que son filósofos los que pueden alcanzar lo que se comporta siempre e [sic] idénticamente del mismo modo, mientras no son filósofos los incapaces de eso, que, en cambio deambulan en la multiplicidad abigarrada,

¿Quiénes [sic] de ellos deben ser jefes de Estado?

-¿Cómo podríamos responder algo razonable?

- A los que de ellos se revelan capaces de vigilar las leyes y costumbres del Estado, a ésos instituiremos como guardianes ${ }^{4}$. (Platón, 1988, p. 295)

La propuesta Platónica tiene vínculo con el arte clásico griego, puesto que las elaboraciones de los bustos de grandes filósofos aluden al dios Apolo5; quien simboliza: orden, simetría y proporción. Por su parte, el retrato costarricense retoma la figura apolínea en una edad madura, íntegra y sinónimo de experiencia.

A nivel iconográfico, la obra del mandatario responde al ideal europeo. Aquiles Bigot (artista francés) fue el encargado de la obra y fomentó la idea de una nación occidentalizada e independiente; principalmente, al incorporar detalles (signos o símbolos) en el cuadro. Por ejemplo, agregó el Escudo de Armas en el retrato, el cual ejemplificó el periodo de transición política de Jefe de Estado a Presidente y con ello una dimensión ideológica.

\footnotetext{
${ }^{3}$ Iconografía e Iconología son dos términos empleados por la Historia del Arte para estudiar una imagen; es decir, ambos conceptos constituyen la unión de una metodología formal para facilitar un argumento (significado) a la obra observada (Calvo, 2012, p. 22).

${ }^{4} \mathbf{4 8 4} \boldsymbol{b}$. Alude a la interrogante de quién es más acto para dirigir un pueblo.

${ }^{5}$ Para Jean Chevalier (1986) Apolo “(...) realiza el equilibrio y la armonía de los deseos, no por suprimir las pulsiones humanas, sino por orientarlas hacia una espiritualización progresiva, gracias al desarrollo de la conciencia” (p. 111).
} 
Justamente, como señala Umberto Eco: "La ideología es un mensaje que partiendo de una descripción factual intenta su justificación y gradualmente se incorpora a la sociedad como elemento del código" (1999, p. 157). Las pretensiones pre-iconográficas $^{6}$ e iconográficas $^{7}$ interactúan como elementos decodificables y vinculantes a la denotación ${ }^{8}$ - connotación ${ }^{9}$. Así, el rostro a nivel pre-iconográfico y correlativo a la denotación implica la figura de un político. Por su parte, la iconografía y vinculada a la connotación

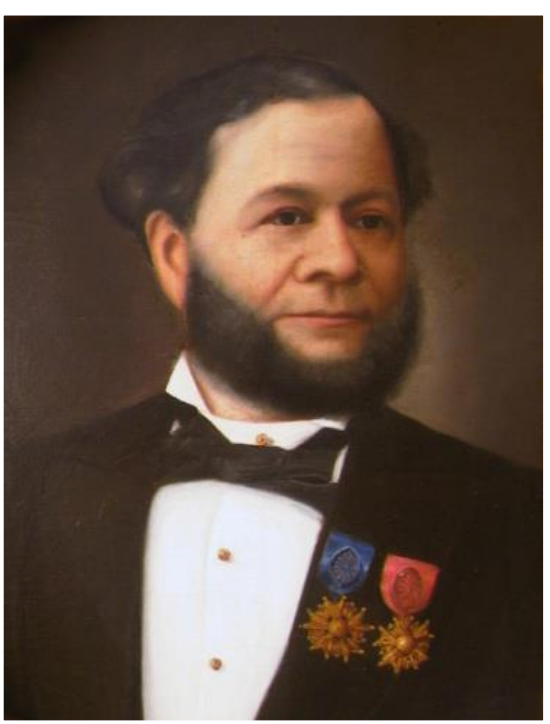

FIGURA 1. Aquiles Bigot. Retrato de José María Castro Madriz. 1878. Óleo sobre tela. Autor de la fotografía: Minor Solís. Pinacoteca de la Asamblea Legislativa de Costa Rica

Madriz (Figura 1).

Al identificar los elementos y, por ende, un significado, se llega a la iconología; comprendida por Panofsky (2004) como: el estudio sobre la manera en que, en distintas condiciones históricas, las tendencias esenciales de la mente humana fueron expresadas mediante temas y conceptos específicos (p. 47). Así, el último estadio de la Iconografía implica: un espacio para la interpretación.

\footnotetext{
${ }^{6}$ Compuesto por dos tipos de significado el fáctico y el expresivo. El significado fáctico es aquel aprendido al identificar ciertas formas visibles con ciertos objetos por el investigador en este caso, identificar que se investigará un retrato. El significado expresivo considera que para comprender se necesita cierta sensibilidad, son matices psicológicos dentro del sujeto. De esta manera, las formas puras (líneas, colores, etc.) son portadoras de significados primarios o naturales en el mundo de motivos artísticos, pues hacen una descripción pre-iconográfica de las obras de arte. (Panofsky, 2004, p. 47)

${ }^{7}$ Cuando se interpreta se reconoce un significado, este es inteligible y ha sido aplicado conscientemente a la acción práctica que lo transmite. Esto permite relacionar los motivos artísticos y las combinaciones de motivos artísticos (compasiones), con temas o conceptos. Tales motivos reconocidos pueden ser llamados imágenes y las combinaciones de imágenes son los que los antiguos teóricos llamaron invención (Historias o alegorías), la identificación de estas alegorías es lo que se llama Iconografía. (Panofsky, 2004, p. 48)

${ }^{8}$ Llamamos DENOTATIVAS a las marcas cuya suma (o jerarquía) constituye e identifica la unidad cultural a que corresponde el significante en primer grado y en que se basan las connotaciones sucesivas (Eco, 1988, p. 142).

${ }^{9}$ En cambio, llamamos CONNOTATIVAS a las marcas que contribuyen a la constitución de una o más unidades culturales expresadas por la función semiótica constituida previamente (Eco, 1988, p. 142).
} 
A nivel iconológico la imagen de José María Castro Madriz proyecta los frutos del compromiso político; por ejemplo: la declaración de una Costa Rica republicana, soberana e independiente, el 15 de setiembre como festiva independiente, la apertura de Limón al comercio exterior, a la vez, de establecer la línea telegráfica entre San José y Cartago. Por último, fue el promotor de la iconografía patria al crear junto con su esposa Pacífica Fernández la bandera que representa nuestro país desde 1848 .

De este modo, como señala Adriana Silvetri y Guillermo Planck, todo signo tiene un fin social y, por ende, un carácter ideológico. Así, "la esfera valorativa de un grupo social particular es la totalidad de lo que reviste importancia y significado para ese grupo" (1993, p. 53). De tal forma, los costarricenses rememoran el gallardete nacional al escuchar el nombre de José María Castro Madriz y su consorte. No obstante, la bandera costarricense deviene de la cultura occidental como enfatiza María Isabel Carvajal (2013):

Se dice popularmente que la señora Fernández "se inspiró" en los colores de la bandera de Francia y en lo que ella representaba: los ideales de la Revolución Francesa. Los conceptos positivistas de orden y progreso tópicos culturales del siglo XIX, se ven afianzados por elementos que refuerzan esta visión de mundo, como los sentimientos de pertenencia a una región, característicos de una Estado nacional. (p. 53)

Además, en la iconografía costarricense se esboza una analogía con los ideales de la Revolución Francesa: “libertad, igualdad y fraternidad” (a pesar de que el contexto histórico y sociocultural, no sea el mismo que el francés). Costa Rica crea el imaginario de considerarse iconográficamente y políticamente como un europeo; y por consiguiente, acopia una ideología visual en la proyección de su imagen internacional. Desde esta perspectiva, Žižek (2008) recalca:

La palabra "ideología" puede designar cualquier cosa, desde una actitud contemplativa que desconoce su dependencia de la realidad social hasta un conjunto de creencias orientadas a la acción, desde el medio indispensable en el que los individuos viven sus relaciones con una estructura social hasta las ideas falsas que legitiman un poder político dominante. (p. 10) 
La política costarricense, entonces, se consagra en la proclama de ideales impropios, lo cual legitima políticamente y crea un imaginario iconográfico; tanto en la elaboración retratística de sus gobernantes como en la representación de emblemas, instituciones, entre otros. Precisamente:

La colonialidad del poder, del saber y del ser se pone de manifiesto al asumir y presentar como representación oficial del país los mismos colores de la bandera de Francia, lo que implica el reconocimiento a Europa como instancia de poder, de racionalidad, de superioridad en todos los sentidos. (Carvajal, 2013, p. 54)

Del tal modo, el retrato de José María Castro Madriz es la réplica de los eslabones visuales europeos. Persiste un espectro ideológico, como señala Žižek (2008), pues se externaliza (representa) un imaginario que no corresponde con la realidad. Una Costa Rica afrancesada con un pasado colonial. Así, el costarricense se ha representado como europeo y ha implantado una ideología imaginaria que se proyecta también en la confección retratística.

\section{Marco y emblemática de la Pinacoteca de la Asamblea Legislativa de Costa} Rica

El marco artístico se concibe como un espacio de entronización para colocar una obra artística. Su inicio data desde la antigüedad, el cual se pintaba una línea gruesa para entornar un dibujo o pintura; asimismo, fue empleado en la Edad Media con el uso del retablo. Posteriormente, en el Renacimiento y el Barroco se da la proliferación de pinturas con marco, dado a la alta demanda de encargos.

Entre las funciones más relevantes del marco artístico se encuentran la protección y el soporte de la obra; sin dejar de lado el valor simbólico de las representaciones inscritas, como es el caso de los marcos pertenecientes a la Pinacoteca de la Asamblea Legislativa. En el caso costarricense, el marco alude a una iconografía occidental y, por lo tanto, el signo ideológico, en cuanto a las características nacionalistas fomentadas. 
Según Fernández (1997) las fotografías de finales del siglo XIX testimonian que los marcos originales de la colección retratística eran sencillos y rectangulares (p. 19). Los marcos fueron cambiados en la administración de José Joaquín Rodríguez Zeledón (1890-1894) y fueron diseñados por tallistas italianos. Asimismo, coincide con el proceso de ornamentación del Teatro Nacional de Costa Rica (Fernández, 1997, p. 19).

El retrato y el marco presentan narrativas visuales que en el plano de lo simbólico se asocian a una ideología y emblemática europea. Lorenzo Vilches (1999) en el campo cinematográfico señala que el marco juega un papel semejante en la pintura, puesto que "El encuadre delimita el espacio representado instalando una diferencia (que puede ser una ruptura simbólica) entre el campo como espacio visible y fuera de campo como espacio invisible" (p. 113).

Al aplicar la observación de Vilches a la Pinacoteca de la Asamblea Legislativa, todos los retratos cuentan con la misma elaboración ornamentaría, los cuales, como se analizará más adelante, corresponden a una iconografía neoclásica y barroca con ideales que no coinciden con el legado del arte prehispánico. De este modo, hay un espacio visible que conmemora la idea de una Costa Rica europeizada y su auténtico espacio es invisible.

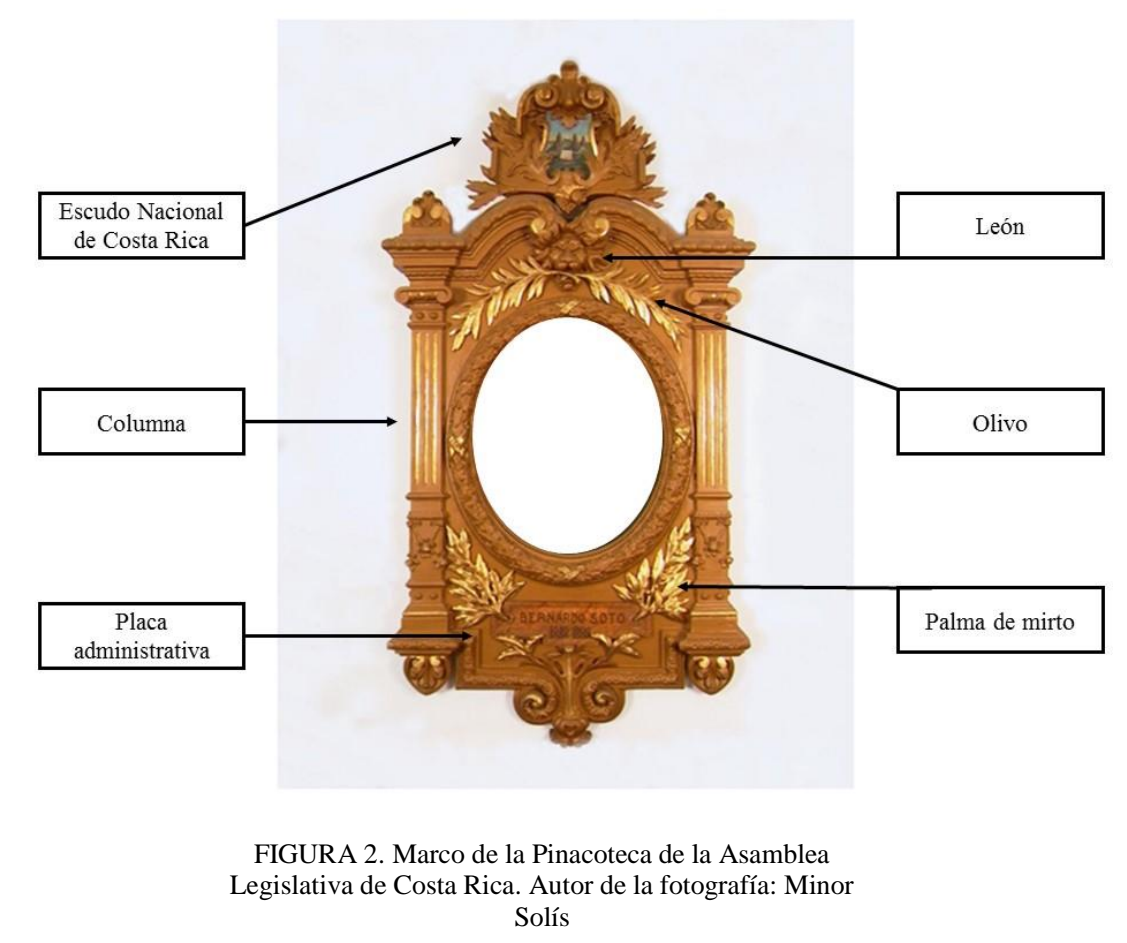




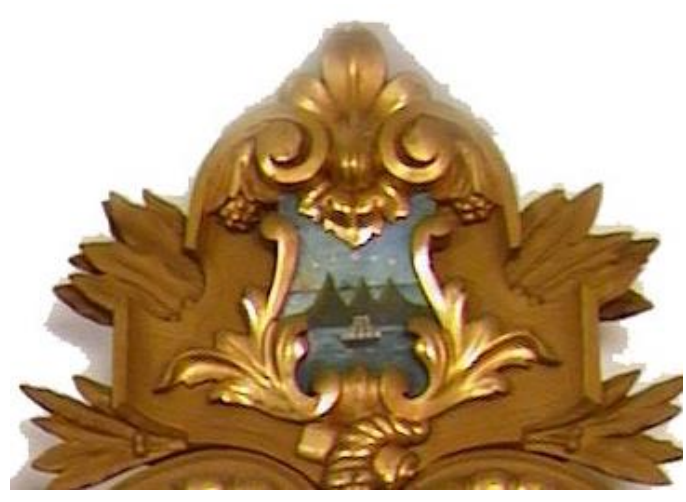

FIGURA 3. Detalle (Escudo Nacional) en el marco de los retratos de la Pinacoteca. Autor de la fotografía: Minor Solís

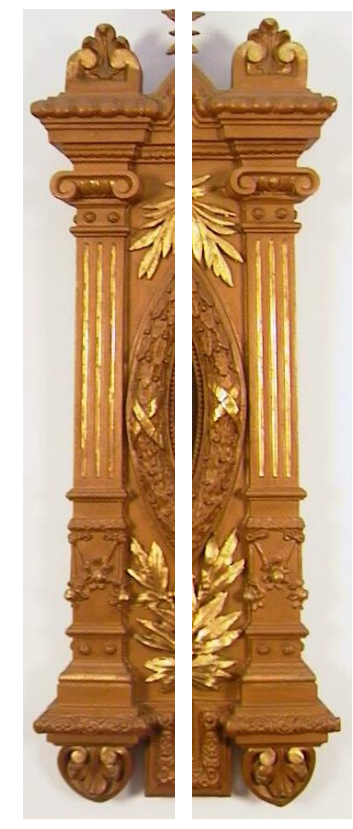

FIGURA 4. Columnas jónicas en el marco de los retratos de la Pinacoteca. Autor de la fotografía: Minor Solís
En efecto, el marco (Figura 2) se alude a varios elementos que no corresponden a un asidero autóctono. Es fundamental señalar que en la administración de José Joaquín Rodríguez Zeledón se proyecta el inicio de la reforma liberal (que luego prosigue su yerno Rafael Iglesias Castro); y se empieza la construcción del Teatro Nacional (18901897), por lo que ideológicamente la contratación de los marcos se circunscribe en el proyecto cultural de finales del siglo XIX.

El primer elemento característico del marco es el Escudo Nacional Costa Rica (Figura 3), este ha variado en cuanto a la representación; por ejemplo, las cordilleras son pintadas en forma de montañas y los bucles son representados, en algunos casos, con dirección opuesta. A pesar de las distorsiones pictóricas, se ha actualizado la iconografía con el último diseño oficial.

Otro rasgo del marco es la representación de dos columnas (Figura 4) que corresponden al jónico griego (Figura 5). Las columnas interactúan como dos pilares que sostienen la parte central del marco. Equitativamente, “(...) al igual que la cultura griega persiste el uso de una duplicidad simbólica: una 
utilidad ingenieril y una estética del diseño arquitectónico, cuyo significado es la elevación (Calvo, 2012, p. 127).

Se debe agregar que en la parte central superior del marco se representa un león (Figura 6). Según Chevalier (1999) el animal simboliza poder y justicia (p. 637). La fiera sujeta en el hocico una rama de olivo, la cual, como señala Calvo (2012), es una planta asociada al dios griego Apolo, por lo que apela al orden, simetría y armonía de las partes; estas particulares se asocian con el poder del dios sobre la humanidad (p. 130). Igualmente, aparece una palma de mirto (Figura 7), la cual simboliza: la victoria, la ascensión, la regeneración y la inmortalidad.

Por último, se encuentra la placa administrativa (Figura 8) ubicada en la parte inferior del marco. Esta reivindica el nombre del regente y los años gobernados.

En síntesis, el marco alude a lo siguiente:

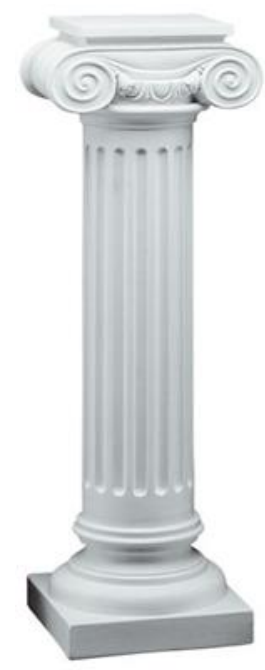

FIGURA 5. Columna Jónica. Mármol. Grecia

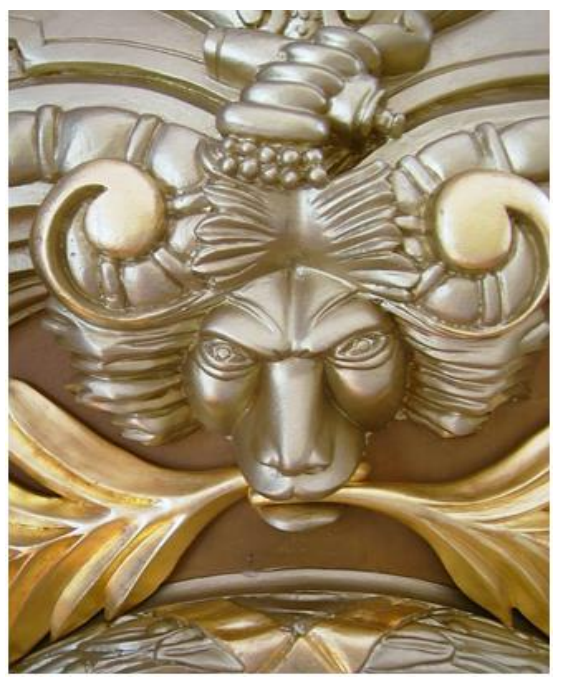

FIGURA 6. Detalle (León) del marco de los retratos de la Pinacoteca. Autora de la fotografía: Andrea Calvo Díaz 


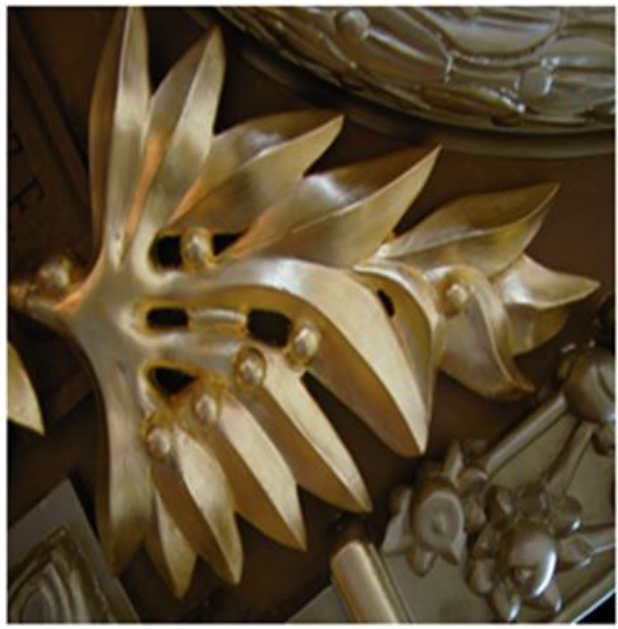

FIGURA 7. Detalle (Palma de mirto) del marco de los retratos de la Pinacoteca de la Asamblea Legislativa. Autora de la fotografía: Andrea Calvo Díaz

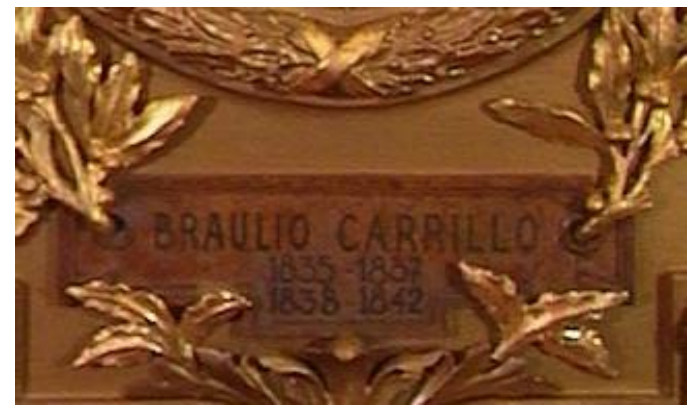

FIGURA 8. Detalle (Placa) del Marco de los retratos de la Pinacoteca de la Asamblea Legislativa. Autor de la fotografía: Minor Solís
Las columnas implican el sostén del gobernador en la toma de decisiones, el león encarna la justicia y la delegación asertiva, la corona de olivo alrededor del retrato refleja un orden de acción, la palma destaca un periodo de regeneración muy acorde a las diferentes administraciones en una nación democrática y, por último, la placa es el reconocimiento público que exalta la labor realizada por el gobernador elegido (Calvo, 2012, p. 132).

Desde esta perspectiva, Eugenio Herranz (1975) en el texto El marco en la Historia del Arte destaca que el efecto del marco barroco es continuo y genera un efecto abarcador, pues desde el primer motivo al último, el espectador no sabe cuál elegir, y termina por preferir toda la pieza en orden de importancia (p. 39). Este efecto totalizador del marco reguarda paralelismo con el poder gubernativo como dispositivo ideológico, pues la iconografía se ajustó al canon europeo como discurso visual.

Así, el poder que ejerce el marco en la Sala de Expresidentes de la Asamblea Legislativa implica una idealización afrancesada, a la vez de representar un imaginario político que no corresponde a la historia y vivencias del costarricense. 


\section{Acopio retratístico en otras manifestaciones visuales: el caso de Braulio Carrillo Colina}

Algunos de los retratos de la Pinacoteca de la Asamblea Legislativa han sido utilizados como referentes para obras conmemorativas, entre ellas la notafilia. Un caso específico es el retrato de Braulio Carrillo Colina (1800- 1845) (Figura 9), si bien es cierto, la autoría del retratista ha sido desconocida, el estudio de Fernández (1997) presume que el retrato del gubernativo es una copia reducida del original y pintado por el francés Nicolás Jaury (p. 98).

El político cartaginés realiza su preparación académica en la Universidad de León de Nicaragua donde se licencia como abogado. Entre los principales cargos públicos se destacan: Presidente del Congreso de Costa Rica, así como Magistrado y Presidente de la Corte Suprema de Justicia; se debe agregar que gobernó a Costar Rica del 5 de mayo de 1835 al 1 de marzo de 1837 como Jefe de Estado. Una de las características de la administración de Braulio Carrillo fue la lucha por una Costa Rica Soberana, tras reusar ser parte de la República Federal de Centroamérica, liderada por Francisco Morazán (1792- 1842).

Empero, Costa Rica elige en 1837 a Manuel María Aguilar (1797-1846) como nuevo Jefe de Estado. El gubernativo pretendía continuar en la República Federal de Centroamérica. De este modo, los aliados de Carrillo derrocan la nueva elección y el político gobierna del 27 de mayo de 1838 al 12 de abril de 1842 bajo una dictadura (aunque la causa inicial es la soberanía costarricense). Sin embargo, como destacan Chacón, Sáenz y Villalobos (2000): 


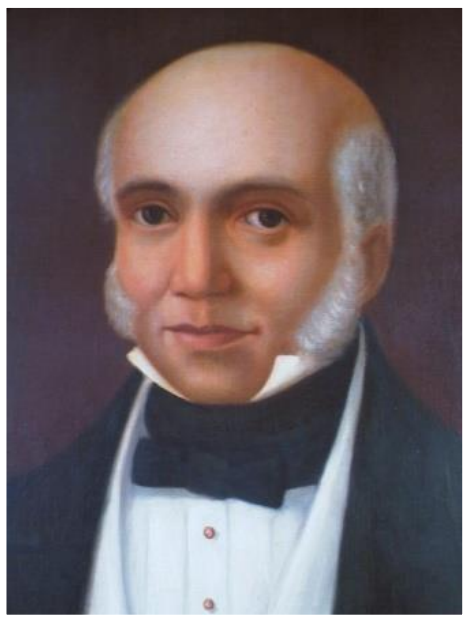

FIGURA 9. Pintor Anónimo. Retrato de Braulio Carrillo Colina. Sin Fecha. Óleo sobre tela. Autor de la fotografía: Minor Solís. Pinacoteca de la Asamblea Legislativa de Costa Rica
(...) la separación definitiva de Costa Rica de la República Federada de Centroamérica, en noviembre de 1838, marcó en realidad nuestra verdadera independencia; el intento de Morazán por engancharnos de nuevo al "tren federal" no tuvo éxito: fue un breve interregno de sólo cinco meses. El alumbramiento del Estado Soberano, uno de los anhelos de Carrillo, profundo conocedor del entorno político y social del país era ya un hecho incontrovertible (p. 112).

Entre los principales logros políticos de Braulio Carrillo se destacan: el paso vial entre el Valle Central y el Caribe costarricense (actualmente una carretera lleva su nombre), la abolición de la Ley de Ambulancia y la estipulación de San José como capital de Costa Rica, la reducción de los días feriados y la promoción del trabajo en contra de los vicios y la vagancia, todavía cabe señalar la consolidación del Código General del Estado de Costa Rica y el decreto de la Ley de Bases y Garantías. Igualmente, impulsa el café como producto nacional, aspecto que lo hace acreedor visual en diversas imágenes relativas al cultivo y la economía del país.

Precisamente, la efigie de Braulio Carrillo ha sido motivo de representación en diversos billetes ${ }^{10}$. En el presente artículo, se utiliza como ejemplo el último billete emitido por el Banco Central de Costa Rica con un valor de 1000 mil colones (Figura 10), el cual presenta un vínculo con el retrato de la Pinacoteca de la Asamblea Legislativa.

\footnotetext{
${ }^{10}$ Las emisiones corresponden a las siguientes: Emisiones de 1900 a 1917 Banco Anglo Costarricense. SERIE "A” Billete de 5 colones. (Carranza, 200, p. 18). Emisiones de 1937-1950 Banco Nacional de Costa Rica. SERIE "G” Billete de 5 colones. (Carranza, 2001, p. 178). Emisiones de 1950 Banco Central de Costa Rica. SERIE "A" Billete de 5 colones (Carranza, 2001, p. 180).
} 

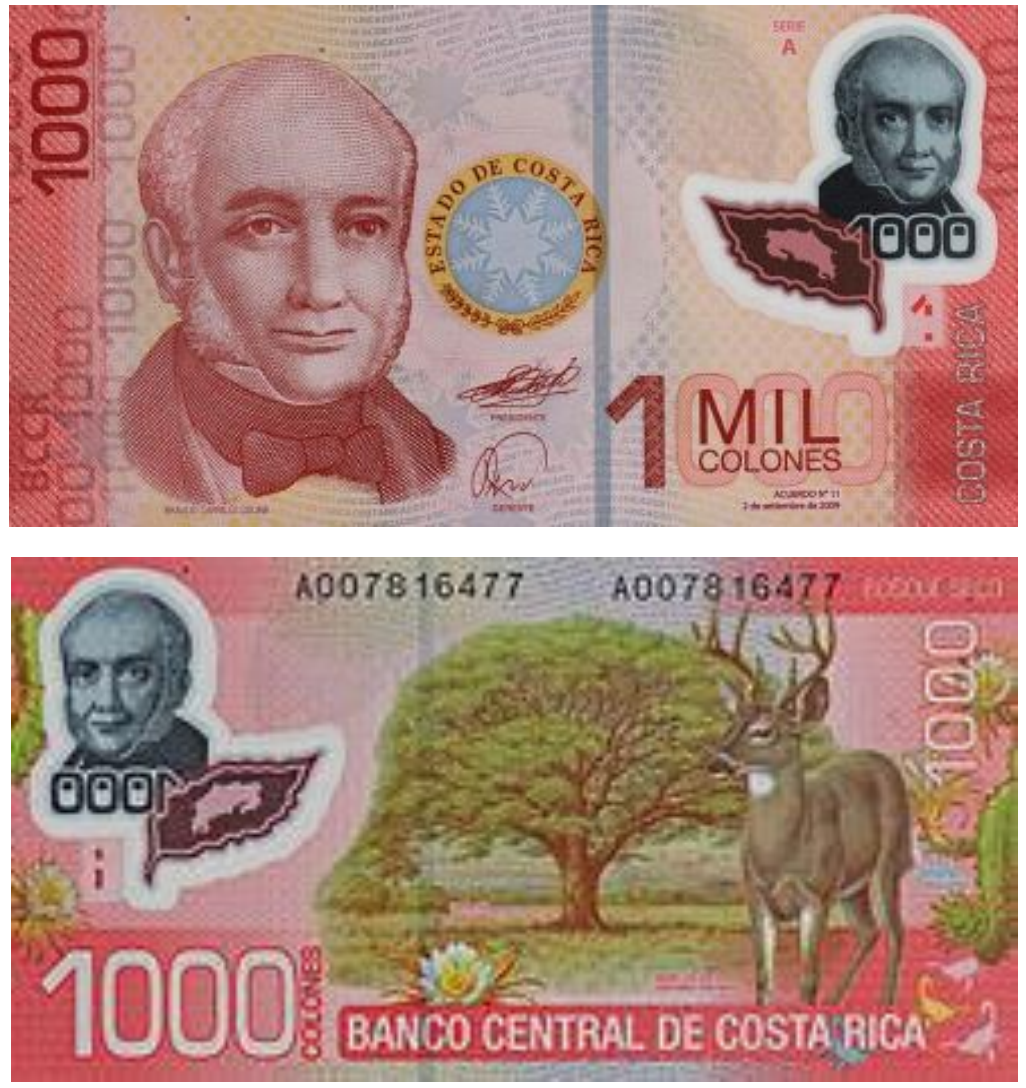

FIGURA 10. Emisión 2012. Banco Central de Costa Rica. Billete de 1000 colones. Fuente: Banco Central de Costa Rica

De este modo, se empieza por considerar el nivel preiconográfico, en el cual se destaca la figura del político, un escudo que contiene la frase: Estado de Costa Rica y una valoración económica de 1000 mil colones. Por su parte, en el reverso del billete se representa un venado cola blanca ${ }^{11}$, el árbol de Guanacaste ${ }^{12}$ y el entorno corresponde al bosque seco ${ }^{13}$. Por su parte, a nivel iconográfico se

\footnotetext{
11 "Decreto Ejecutivo ํ7497 que declara al venado cola blanca como símbolo de la fauna silvestre de Costa Rica", $L a$ Gaceta: diario oficial. (San José, CR), 8 de junio, 1995. (Alc.20110), p. 28.

${ }^{12}$ Decreto Ejecutivo №7 que declara el árbol de Guanacaste como símbolo nacional”, La Gaceta: diario oficial. (San José, CR), 3 de setiembre, 1959. (198), p. 32-31.

${ }^{13}$ El bosque tropical seco es aquel que existe en áreas donde casi no llueve durante tres meses del año (enero, febrero y marzo) y, por ello, los árboles botan las hojas para ahorrar energía. Así sucede en sitios como Guanacaste. Esta falta de verdor durante una parte del año, así como el tipo de suelo y la temperatura, hace que muchas personas no los reconozcan como bosques, y por eso, algunas de estas áreas han sido taladas, quemadas o urbanizadas (Suplemento: Costa Rica al Natural. Bosque seco. La Nación, 16 de mayo, 2012).
} 
identifica que el billete es una conmemoración de la obra de Braulio Carrillo y, como señala Castro (2014):

No es la primera vez que se utiliza el retrato de Carrillo para un billete nacional, de hecho las reproducciones artísticas guardan ciertos parámetros comunes como el ángulo de la cabeza y la miradas hacia el espectador, esté último sin duda es un recurso incorporado por el artista, que mediante el cruzado de miradas entre el espectador y la obra establece una cierta cercanía e identificación de la figura como una representación humana (p. 196).

Desde esta perspectiva, la imagen del billete adquiere una valía ideológica, pues interactúa como un dispositivo visual que establece relaciones de poder a través del significado (en este caso político). En palabras de Althusser (2005):

El Estado es una "máquina” de represión que permite a las clases dominantes (en el siglo XIX a la clase burguesa y a la "clase" de los grandes terratenientes) asegurar su dominación sobre la clase obrera para someterla al proceso de extorsión de plusvalía (es decir de explotación capitalista) (p. 20).

Siguiendo al autor, la represión que ejerce el Estado utiliza aparatos ideológicos (asumidos como instituciones que controlan el poder) y que funcionan mediante la ideología ${ }^{14}$ (2005, p. 30). En el presente artículo median dos aparatos ideológicos: el político y el cultural, pues la mayoría de las representaciones que asume la iconografía patria son gestadas a partir de los avales políticos y culturales de Europa. Igualmente, los retratos de la Pinacoteca de la Asamblea Legislativa se han desempeñado como aparatos ideológicos; puesto que son formulados a partir de la superestructura política.

Al mismo tiempo, las representaciones que esbozan la memoria histórica costarricense emplean a la cultura (aparato ideológico) como recurso pedagógico. Así, a nivel iconológico se busca

\footnotetext{
${ }^{14}$ Para el autor, la ideología se comprende como: una representación de la relación imaginaria de individuos con sus condiciones reales de existencia" (Althusser, 2005, p. 52).
} 
la identificación de un motivo y es preciso aclarar que el presente artículo ha estudiado el retrato de Braulio Carrillo Colina y su relación con la notafilia a partir de la recepción social del costarricense.

Así, el espectador ${ }^{15}$ al apreciar el billete de 1000 colones, se dirige no solo al valor económico, sino a la iconografía proyectada. Según Castro (2014), el discurso visual de la notafilia de la familia de billetes 2011 proyecta dos finalidades; por un lado, la historia política de Costa Rica y la transcendencia de su soberanía ${ }^{16}$, así como la propaganda turística y ecológica (Castro, 2014, p. 230). De esta forma, se infiere que muchos de los retratos de la Pinacoteca de la Asamblea Legislativa son referentes visuales para la creación de imágenes, a la vez de estar ligadas a relaciones de poder y proyectos ideológicos.

\section{Epílogo}

La Pinacoteca de la Asamblea Legislativa de Costa Rica toma como referente el canon europeo, tanto en la asimilación visual (iconográfica) como ideológica. De tal forma, las diversas administraciones políticas procuraron ataviar el referente europeo en la elaboración retratística y la del marco (uso de ornamentos neoclásicos y barrocos). Asimismo, se fomentan ideales nacionalistas de origen francés para exaltar un imaginario impropio.

De ahí que el Estado costarricense encuentra en la política y la cultura instrumentos para controlar y ejercer poder. Así, la colección de retratos implica un dispositivo visual e ideológico, pues se enaltece al político como gran pensador (por ejemplo, José María Castro Madriz). A la misma vez,

\footnotetext{
${ }^{15}$ Es fundamental recalcar que para Althusser (2005), la ideología interpela a los individuos como sujetos. Es decir, la ideología solo existe por el sujeto y para los sujetos (p. 64).

${ }^{16}$ La iconografía presente en el billete de 1000 mil colones de la Emisión del 2012, no solo reprime por ser un parte de un aparato ideológico del estado (Cultura y Política), sino que también absuelve, puesto que la figura de Braulio Carrillo ha sido expiadada a nivel iconográfico, esto tras no comprender la relevancia de su decisión en tiempos pasados.
} 
se valora el retrato para replicas visuales como la notafilia del billete de 1000 colones de la Emisión 2012 (caso de Braulio Carrillo Colina).

\section{Referencias bibliográficas:}

Althusser, L. (2005). Ideología y Aparatos Ideológicos del Estado. (M. Mandujano, tr.). Distrito Federal: Ediciones Quinto Sol.

Belting, H. (2007). Antropología de la imagen. (G. Vélez, tr.). Madrid: Katz Editores.

Blanck, G; Silvestri, A. (1993). Batjín y Vigotsky: La organización semiótica de la conciencia. Barcelona: Anthropos.

Calvo- Díaz, A. (2012). Análisis Iconográfico y Hermenéutico de la Pinacoteca de la Asamblea Legislativa. Jefes de Estado y Presidentes de la República. (Tesis de Licenciatura en Historia del Arte). Universidad de Costa Rica, Sede Rodrigo Facio.

Carranza, J. (2001). Historia de los billetes de Costa Rica 1858-2011. San José: Fundación de Museos del Banco Central de Costa Rica.

Carvajal- Araya, M. (2013). Construcción del imaginario costarricense a través de los símbolos nacionales. Tesis de Doctorado en Estudios de la Sociedad y la Cultura). Universidad de Costa Rica, Sede Rodrigo Facio.

Castro- Madriz, J. (2014). Análisis estético, iconológico e iconográfico de la nueva familia de billetes de papel moneda de Costa Rica 2009-2011 y sus antecedentes. (Tesis de Maestría Académica en Artes Visuales). Universidad de Costa Rica, Sede Rodrigo Facio.

Chacón, L; Sáenz, J; Villalobos, J. (2000). Braulio Carrillo. El Estadista. Tomo II. San José: Imprenta Nacional. 
Chevalier, J. (1986). Diccionario de Símbolos. (M. Silver y A. Rodríguez, tr.). Barcelona: Editorial Herder.

Eco, U. (1999). La Estructura Ausente. Introducción a la Semiótica. (F. Serra, tr.). Barcelona: Editorial Lumen.

Eco, U. (1988). Tratado de Semiótica. Barcelona: Lumen.

Fernández, L. (1997). Pinacoteca del Poder Legislativo Costarricense. San José: Imprenta

Panofsky. E. (2004). El significado de las artes visuales. (N. Ancochea, tr.). Madrid: Alianza. Platón. (1988). República. (C.Eggers, tr.). Madrid: Editorial Gredos.

Vilches, L. (1999). La lectura de la imagen. Prensa, cine, televisión. Barcelona: Editorial Paidós.

Vitta, M. (2003). El sistema de las imágenes. Estética de las representaciones cotidianas. (M. Martí, tr.). Barcelona: Editorial Paidós.

Žižek, S. (compilador). (2008). Ideología. Un mapa de la cuestión (C. Beltrane, tr.). Buenos Aires: Fondo de Cultura Económica de Argentina.

\section{(c)}

